\title{
Advanced vibration management to improve productivity and optimize cost for excavation of iron ore: A case study
}

\author{
Debashish Mukherjee and Rajesh Kumar \\ Tata Steel Ltd. \\ Jamshedpur, India \\ d.mukherjee2@tatasteel.com
}

\begin{abstract}
A major concern in deep hole blasting in open cast mining operation is the excessive generation of ground vibration and their effect on nearby industrial infrastructures and residential dwellings of local community. A poor blast output results in lower productivity of excavators which has a paramount adverse effect on overall cost structure of mining operation. Drilling and blasting cost comprises a significant part of the overall operations and maintenance cost in an open cast excavation process. The paper describes the result of systematic study carried out to manage ground vibration and blast output parameters at Joda East Iron Mine, which has an annual excavation of 12.5 MT (FY 16). The study involved detonation of multiple blast holes to determine the effective charge weight per delay and generate site specific empirical equations and constants. A further detailed study was then carried out using stastical - simulation technique to specify the blast designs and delay pattern for reducing the blasted mean particle size of rock strata which has a compressive and tensile strength of 145.3 MPa and 13.6 MPa respectively. The average density of rock is $3500 \mathrm{~kg} / \mathrm{m} 3$. A correlation was then established between drill feed pressure and rock hardness to optimize the explosive charge per delay. The peak particle velocity data were recorded at point of interest. This data was subsequently analyzed for developing the limits of vibration. A correlation model was then established between predicted and actual vibration at point of interest. The result showed approximately $90 \%$ accuracy between these parameters. Electronic delay detonators were introduced for controlling the blast design parameters with variation in the explosive charging methods. A comparative study was then simulated for measuring the cost effectiveness in overall mine to mill operation which resulted in a significant amount of cost saving over the entire value chain. Paper also represented the overall range of cost and blast output parameters in different rock strata of iron ore and has several recommendations for enhancing blast output, which have suitable benefits in mining industry.
\end{abstract}

Keywords—blast ability, peak particle velocity, productivity, pyro technique, specific energy

\section{INTRODUCTION}

Joda East Iron mine is an ISO 9001:2008, ISO 14001:2004, and OHSAS18001:2007 certified captive iron ore mine of Tata Steel Ltd. The mine is situated at about 70 $\mathrm{km}$ South - West of Kendujhargarh in Odisha. The deposit was discovered in 1909. The mine started its operation on $1^{\text {st }}$ April 1956 and spreads over an area of 671.093 ha. The open cast mining operation comprises office preparation, drilling, blasting, loading, hauling and crushing. Blast holes are drilled with $150 \mathrm{~mm}$ dia drill machines as per the excavation plan. Drilling and blasting being the first unit operations, can have a major impact on the performance and cost of other unit operations. The prime objective of these two operations is to obtain optimum fragmentation within safe and economical limits to facilitate the crushing process. The output from the blasting process is dependent on many parameters such as rock composition, layer thickness, orientation of rock, type of loading machine, type of explosives etc. Thus, a quick and accurate evaluation process is required to assess its effective ness. Productivity of excavators plays a pivotal role in mine economics. The rapid release of explosive energy is used to fragment rock and separate from its in situ conditions and blasted material is available for excavation. The economic effect of a good blast is numerous. A well fragmented material optimizes the loading time of excavators and helps in reducing the cycle time. Overall a net increment in duty cycle of HEMMs can be obtained. Little [1] produced a useful summary of a blast which they describe as the "explosives-rock mass interaction." Fig. 1 shows the three areas: blast geometry, loading and timing or blast design; rock mass characteristics; and, explosive characteristics. The rock mass inputs are a function of the geological setting of the orebody. The explosives characteristics are chosen by the blasting engineer based on the rock mass properties and the desired blasting objective. The blast design implements the explosives and initiation sequence given the geology and the available geometry (blast hole diameter, blast hole length, number of decks etc.) to focus the available energy on the blasting objective.

The primary blast outputs (Fig. 1) may be identified visually but a deep insight into it will reveal the exact nature of fragmented rock. Studies and field experiments are required for effectively mapping the blast parameters. The input criteria for blasting include drill geometry, nature of rock, explosives charging methods, delay sequencing, initiation point, no. of holes etc. Generally, output of a blast is measured in terms of ground vibration and fragmentation. 
But there is always something more to it. A well approached pre - blast design will help in finding the better alternatives and as a whole it willlead to better blast outputs. Nonexhaustive list of over fifty variables involved in managing a blastand opines that while some of the variables maybe controlled "this leaves an uncomfortably largenumber of variables whose effect on blastingand subsequent operations has to be assessed." Cunningham [2] offered a broad templatefor the types of measurements that would helpstrengthen the decision-making for a blast designer.It complements the items identified in Fig.1 and is given in Fig.2.

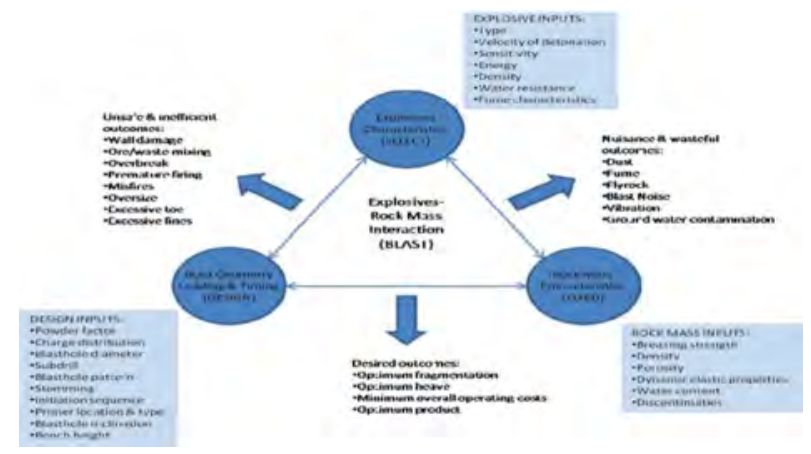

Fig.1. Explosives-rock mass interaction [1]

\begin{tabular}{|c|c|c|}
\hline Pre-blast & In-blast & Post-blast \\
\hline $\begin{array}{l}\text { Geology: } \\
\text { Relevant dynamic } \\
\text { rock characteristics } \\
\text { Water } \\
\text { Rockstructure } \\
\text { Explosives: } \\
\text { Composition } \\
\text { Density } \\
\text { Uniformity } \\
\text { Stability } \\
\text { Sensitivity } \\
\text { Blast Geometry: } \\
\text { Hole profile } \\
\text { Proximity of holes to } \\
\text { surface, each other } \\
\text { and rock structure } \\
\text { Initiation: } \\
\text { Position } \\
\text { Strength and } \\
\text { orientation of primers } \\
\text { etc. } \\
\text { Robustness and } \\
\text { accuracy of system }\end{array}$ & $\begin{array}{l}\text { Detonation velocity } \\
\text { Borehole pressure } \\
\text { history } \\
\text { Relationship between } \\
\text { pressure behind and } \\
\text { ahead of blastholes } \\
\text { Pressure-time history } \\
\text { with distance from } \\
\text { hole } \\
\text { Effect of stress from } \\
\text { multiple holes on } \\
\text { development of } \\
\text { fracture and } \\
\text { movement } \\
\text { Effect of energy } \\
\text { partitioning on } \\
\text { different rock types } \\
\text { Dynamic interaction } \\
\text { of blastholes: } \\
\text { - Sympathetic } \\
\text { - Desensitising } \\
\text {-timing }\end{array}$ & $\begin{array}{l}\text { Condition of } \\
\text { remaining rock } \\
\text { Fragmentation Sizing: } \\
\text { - Fines } \\
\text { - Oversize } \\
\text { - Intermediate } \\
\text { Rockpile shape, } \\
\text { looseness and } \\
\text { movement } \\
\text { Depth of break } \\
\text { Fumes }\end{array}$ \\
\hline
\end{tabular}

Fig.2. Blast monitoring zones [2]

\section{BlastabiLity AND GROUND ViBRATION PREDICTOR}

Rock mass comprises several different rock types and is affected by different degrees of fracturing in varying stress condition. A number of rock mass classification or rating have been developed for Geo-technical purposes like Rock Quality Designation (RQD), Q-Index [9], Rock Mass Rating (RMR) [10], the major joint sets. Hino [8] proposed that blastability (named as Blasting Coefficient (BC)) is the ratio of compressive strength (CS) to tensile strength (TS) ofrock mass, which may be given as follows.

$$
\mathrm{BC}=\mathrm{CS} / \mathrm{TS}
$$

A factor is to represent the influence of rock and defined by $\mathrm{C} 0$, when it refers to a limit charge (zero throw condition). $\mathrm{C}$ indicates the value of the factor including a technical margin for satisfactory breakage, and is given by $\mathrm{C}=1.2 \times \mathrm{C} 0 . \mathrm{C} 0$ has a value of $0.17 \mathrm{~kg} / \mathrm{m} 3$ for crystalline granite (found from a number of trial blasts in brittle crystalline granite) and has value between 0.18 to $0.35 \mathrm{~kg} / \mathrm{m} 3$ for other rocks. For blast designs, $\mathrm{C}=0.4 \mathrm{~kg} / \mathrm{m} 3$ is considered directly and with the incorporation of desired tendency for breakage and throw based on geological and design parameters alteration in powder factor is required.Fraenkel (1954) proposed the following empirical relationship between the height and diameter of the charge, hole depth, maximum burden and blastability.

$$
\mathrm{S}=\left(50 \times \mathrm{V}_{\max }\right) /\left(\mathrm{h}^{0.3} \times \mathrm{H}^{0.3} \mathrm{x} \mathrm{d}^{0.8}\right)
$$

where,

$$
\begin{aligned}
& \mathrm{S}=\text { Blastability, } \mathrm{Vmax}=\text { Maximum Burden }(\mathrm{m}), \\
& \mathrm{H}=\text { Depth of hole }(\mathrm{m}), \mathrm{h}=\text { Charge height }(\mathrm{m}) \text { and } \\
& \mathrm{d}=\text { Charge diameter }(\mathrm{mm})
\end{aligned}
$$

Ground Vibration induced by blasting process has raised many problems for the local inhabitants residing in the core and buffer zone affected by mining operations. Some of the effects are damage in houses, unwanted noise, and dust: which has resulted in loss of trust for mining community. Though the problem is large as it encounters the stake holders of mining industry but it can be resolved with a planned scientific approach. Blast induced ground vibration which is propagated in rock can be divided into two categories viz. body waves and surface waves.

The damage criteria was proposed by many organizations including USBM, DGMS, Indian Standards etc. based on the Permissible PPV in $\mathrm{mm} / \mathrm{s}$ and Frequency of the ground vibrations for various types of structures. The criteria based on the Permissible PPV in $\mathrm{mm} / \mathrm{s}$ and Frequency of the ground vibrations for various types of structures as per DGMS [4] as presented below in Table I and II is followed for the present investigations to estimate safe charge per delay to limit the ground vibrations within safe limit.

TABLE I. DAMAgE CRITERIA VIS-Á-VIS BUILDINGS/STRUCTURES BELONGING TO THE OWNER

\begin{tabular}{|l|l|l|l|}
\hline \multicolumn{1}{|c|}{ Type of Structure } & \multicolumn{3}{c|}{ Dominant Excitation Frequency } \\
\hline \multicolumn{1}{|c|}{ (PPV in mm/sec) } & $<8 \mathrm{HZ}$ & 8 to $25 \mathrm{HZ}$ & $>25 \mathrm{HZ}$ \\
\hline a) Domestic Houses & 5 & 10 & 15 \\
\hline b) Industrial Buildings & 10 & 20 & 25 \\
\hline c) Sensitive Structure & 2 & 5 & 10 \\
\hline
\end{tabular}

TABLE II. DAMAGE CRITERIA VIS-Á-VIS BUILDINGS/STRUCTURES NOT BELONGING TO THE OWNER

\begin{tabular}{|l|l|l|l|}
\hline Type of Structure & \multicolumn{3}{|l|}{ Dominant Excitation Frequency } \\
\hline (PPV in mm/sec) & $<8 \mathrm{HZ}$ & 8 to $25 \mathrm{HZ}$ & $>25 \mathrm{HZ}$ \\
\hline a) Domestic Houses & 10 & 15 & 25 \\
\hline b) Industrial Buildings & 15 & 25 & 50 \\
\hline
\end{tabular}




\section{A. Predictor equation for ground vibration}

Extensive research has been conducted to determine the mathematical relationship between vibration level, charge size and distance. The relationship is known as the Propagation Law, developed in the U.S Bureau of Mines Bulletin 656

$$
\mathrm{V}=\mathrm{H}\left[\mathrm{D} / \mathrm{W}^{\alpha}\right]^{\beta}
$$

where

$\mathrm{V}=$ Predicted particle velocity (in/s)

$\mathrm{W}=$ Maximum explosive charge weight per delay (lbs.)

$\mathrm{D}=$ Distance from shot to sensor measured in 100's of feet

(e.g.for distance of 500 feet, $\mathrm{D}=5$ )

$\mathrm{H}=$ Particle velocity intercep

$\alpha=$ Charge weight exponent

$\beta=$ Slope factor exponent

The values of $\alpha, \beta$ and $H$ are determined by condition in the area, rock type, local geology, thickness of overburden and other factors. The waves emanating from the blast holes can cause damages to structures nearby to the mining areas. Thus, many of Blast Monitoring Techniques have been advised based on the number of approaches devised by researchers. Some of the approaches for the blast vibration monitoring are listed below in Table III.

TABLE III. PREDICTOR EQUATIONS BY DIFFERENT RESEARCHERS

\begin{tabular}{|c|c|c|}
\hline Approaches & Equation for PPV & $\begin{array}{l}\text { Description of the } \\
\text { Approaches }\end{array}$ \\
\hline $\begin{array}{l}\text { Langefors and } \\
\text { Kihlstrom } \\
\text { Predictor(1963) }\end{array}$ & $\mathrm{V}=\mathrm{K}\left[\sqrt{ }\left(\mathrm{Q}_{\max } / \mathrm{R}^{2 / 3}\right)\right]^{\mathrm{B}}$ & $\begin{array}{l}\text { This formula was based on } \\
\text { early researcher by Langefors } \\
\text { and Kihlstrom into blasting in } \\
\text { hard Swedish granite. }\end{array}$ \\
\hline \begin{tabular}{|l|} 
Ambraseys- \\
Hendron predictor \\
$(1968)$
\end{tabular} & $\mathrm{V}=\mathrm{K}\left[\mathrm{R} /\left(\mathrm{Q}_{\max }\right)^{1 / 3}\right]^{\mathrm{B}}$ & $\begin{array}{l}\text { The USBM investigators } \\
\text { suggested that any linear } \\
\text { dimension should be scaled to } \\
\text { the cube root of the explosive } \\
\text { charge weight for spherical } \\
\text { geometry. An inverse power } \\
\text { law was suggested to relate } \\
\text { amplitude of the seismic } \\
\text { waves and scaled distances to } \\
\text { obtain the mentioned } \\
\text { relationship. }\end{array}$ \\
\hline $\begin{array}{l}\text { Indian Standard } \\
\text { Predictor (1973) }\end{array}$ & $\mathrm{V}=\mathrm{K}\left[\left(\mathrm{Q}_{\max } / \mathrm{R}^{2 / 3}\right)\right]^{\mathrm{B}}$ & $\begin{array}{l}\text { Indian standard suggested that } \\
\text { the blast should be scaled to } \\
\text { the equivalent distance or the } \\
\text { scaled distance; define as the } \\
\text { explosive charge weight } \\
\text { divided by the cube root of } \\
\text { square of the real distance. }\end{array}$ \\
\hline $\begin{array}{l}\text { General Predictor } \\
(1964)\end{array}$ & $\mathrm{V}=\mathrm{KR}^{-\mathrm{B}}\left(\mathrm{Q}_{\max }\right)^{\mathrm{A}}$ & $\begin{array}{l}\text { Number of researchers } \\
\text { (Davies et al 1964; Attewell } \\
1964 ; \text { Birch and Chaffer } \\
1983 \text {; etc.) by considering } \\
\text { particular charge symmetry. }\end{array}$ \\
\hline $\begin{array}{l}\text { Ghosh-Seamon } \\
\text { predictor (1983) }\end{array}$ & $\begin{array}{l}\mathrm{V}=\mathrm{K}\left[\mathrm{R} / \sqrt{ } \mathrm{Q}_{\max }\right]^{-\mathrm{B}} \mathrm{e}^{-\mathrm{\alpha R}} \\
\mathrm{V}=\mathrm{K}\left[\mathrm{R} /\left(\mathrm{Q}_{\max }\right)^{1 / 3}\right]^{-\mathrm{B}} \mathrm{e}^{-\alpha \mathrm{R}}\end{array}$ & $\begin{array}{l}\text { Ghosh-Deamon predictor } \\
\text { proposed that various inelastic } \\
\text { effects cause energy losses } \\
\text { during wave propagation in } \\
\text { various medium. This } \\
\text { inelastic effect leads to a }\end{array}$ \\
\hline
\end{tabular}

\begin{tabular}{|l|l|l|}
\hline & & $\begin{array}{l}\text { decrease in amplitude in } \\
\text { addition to those due to } \\
\text { geometrical spreading. They } \\
\text { modified the propagation } \\
\text { relation of USMB in terms of } \\
\text { adding inelastic attenuation } \\
\text { factor( } \alpha)\end{array}$ \\
\hline $\begin{array}{l}\text { CMRI Predictor } \\
(1993)\end{array}$ & $\begin{array}{l}\text { Pal Roy [5] proposed a new } \\
\text { predictor equation based on } \\
\text { the data collected from } \\
\text { different India geo- mining } \\
\text { conditions. This equation is } \\
\text { valid in the zone of } \\
\text { disturbance, i.e. when Qmax }>0 \\
\text { and V }>0\end{array}$ \\
\hline
\end{tabular}

where

$\mathrm{V}=$ Peak Particle Velocity $(\mathrm{mm} / \mathrm{sec})$

$\mathrm{R}=$ Distance between blast face and monitoring point $(\mathrm{m})$

$\mathrm{Q} \max =$ Maximum explosive charge used per delay $(\mathrm{kg})$

$\mathrm{K}, \mathrm{A}, \mathrm{B}, \alpha=$ Site constants which can be determined by multiple regression analysis

$\mathrm{n}=$ Site constant which is influenced by rock properties and geometrical discontinuities

$\mathrm{k}=$ Site constant which is related to design parameters

\section{Productivity AND Mine Cost}

\section{A. Impact of Blasting}

Rock fragmentation distribution influences a range of mining and milling processes including load and haul rates, crushing and grinding performance and ore recovery in beneficiation processes. In open cast mining operation, blasting is an integral part for achieving cost effectiveness and productivity enhancement. For any excavation process, rock mass properties cannot be controlled but the blast design parameters can be controlled and modified as per the requirements. This approach has a positive impact on the subsequent unit operations. Size of fragmented material primarily depends on the crushing and loading unit. The high-level of mechanization and theintegrated nature of the production systems adopted in the miningindustry demands that all the unitsmust functionwith designed reliability and capacity to achieve planned production targets [6]. HEMM productivity in large open cast mines primarily depends upon the blasted inventory. A good blasted muck profile provides increased efficiency in duty cycle of excavators and dump trucks. Hence drilling and blasting is a critical success factor in improving the overall productivity of a mining unit.

\section{B. Impact on Mine economics}

Broadly the mining cost comprises of statutory cost such as royalty, DMF, NMET etc. and operations cost. Since the statutory cost are fixed, there is an immense advocacy to reduce the mining operations cost so as to operate a sustained mine economics. The other component of fixed cost includes the wages and compensation cost. With all these in the operational purview it becomes very much essential to manage the mining operation cost or the excavation and processing cost. For a typical open cast highly mechanized mines diesel, power and explosives play a major role. An optimization in cost of these elements would add a significant value to the overall mine to mill productivity. A major focus in recent years is to holistically 
view the overall cost incurred in the dispatch of products to customers. For a typical iron ore industry, cost of fines and sized ore dispatched decide the modus operandi of customers. Drilling and blasting being the source unit operation in the overall value chain, acts as the base for overall efficiency of the system. A good fragmented blasted material designed as per the requirements of crushing unit results in higher production and productivity. Mining operation especially blasting faces a tough challenge of implementation of safety in nearby localities due to ground vibration, fly rock etc. This has a detrimental effect on overall blast output parameters as many of the practicing engineers tend to have a more cautious approach comprising on the blast outputs which results in loss of potential improvement in productivity. The use of conventional techniques in charging and stemming methods needs to be upgraded for a better output in the mining sector.

\section{CASE Study :Site AREA}

The south quarry of Joda East Iron mine has potential deposits of hard iron ore. Approximately $4 \mathrm{MT}$ of hard ore has been locked in the upper benches of the south quarry. Along with hard ore the extended part of the quarry needs to be developed for sustainable mining operations. The extended part has different ore types and rejects such as BHJ and non-mineralized zone. But the major challenge in drilling and blasting is the existence of local dwellings and industrial infrastructure within $600 \mathrm{~m}$ of the blast site. The major problem was of nearby residential dwellings which had a considerable amount of population. Hard ore deposits in the south quarry were a vital source of iron ore production and excavation has also been planned in the approved mining scheme.

\section{A. Methodology}

The first approach was to design the blast rounds for higher safety. To implement this various brainstorming sessions were conducted among the experts of blasting field and it was decided to implement Ikon electronic detonators as these have higher accuracy than conventional delay detonators. In order to implement this vibration prediction model was to be determined. Further Amplitude constant ' $\mathrm{K}$ ' and Attenuation constant ' $n$ 'was to be established for the site. Another important job was the determination of ' $\mathrm{P}$ ' wave velocity. A target for $90 \%$ accuracy level between actual and predicted ground vibration was aimed as a deliverable for the experiment.

\section{B. Design of Experiment}

The first step was setting of monitoring stations at point of interest. 3 monitoring stations were set up for recording the ground vibration. Suitable cylindrical cemented base stations were set up for actual reading through seismograph. Signature shots were taken in 3 rounds to determine the sitespecific constants. The input given was predefined charge per delay within a time frame and scaled distance. The output of peak particle velocity and air - blast were recorded in subsequent firing of signature blast holes. Further based on regression analysis site specific constants were determined and later they were validated using the actual data.

\section{Blast Design and Vibration Prediction Model}

Electronic detonators were used for signature shots trial. Drill pattern were determined based on the bench height and nature of strata (compressive strength $145.3 \mathrm{MPa}$ ). 3 rounds of signature shots were taken. Explosive charge weights were kept between $20 \mathrm{~kg}$ and $170 \mathrm{~kg}$ per deck which acted as maximum instantaneous charge. $500 \mathrm{~ms}$ delay was given between each maximum instantaneous charge. Peak particle velocity readings were recorded for each charge per delay. CyCad software was used for determining the site-specific constants. Obtained readings were then plotted against their scaled distance [13].

$$
\mathrm{PPV}=\mathrm{K} \times \mathrm{SD}^{-\mathrm{n}}
$$

where

$$
\begin{aligned}
& \mathrm{SD}=\mathrm{D} / \sqrt{\mathrm{W}} \\
& \mathrm{PPV}=\mathrm{Vibration}(\mathrm{mm} / \mathrm{s}) \\
& \mathrm{SD}=\text { Scaled Distance } \\
& \mathrm{D}=\text { Distance }(\mathrm{m}) \\
& \mathrm{W}=\text { Charge Weight }(\mathrm{kg}) \\
& \mathrm{K} \quad \text { Site Amplitude constant }(\mathrm{PPV} \text { of } 1 \mathrm{~kg} \text { at } 1 \mathrm{~m}) \\
& \mathrm{n} \quad=\text { Site Attenuation constant (rate of decay) }
\end{aligned}
$$

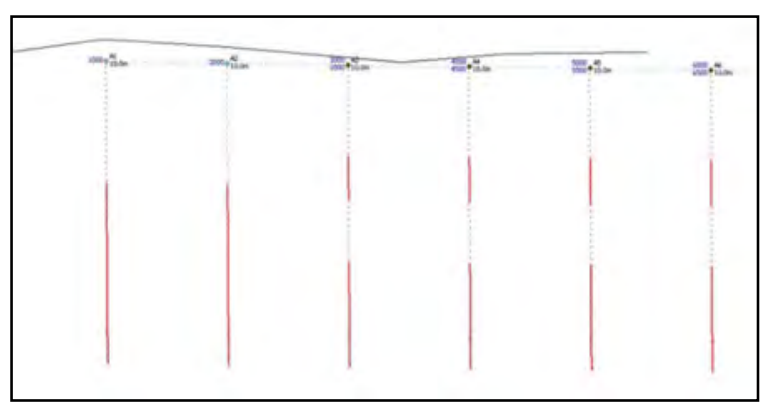

Fig. 3. Delay and charging pattern for each round of signature shot

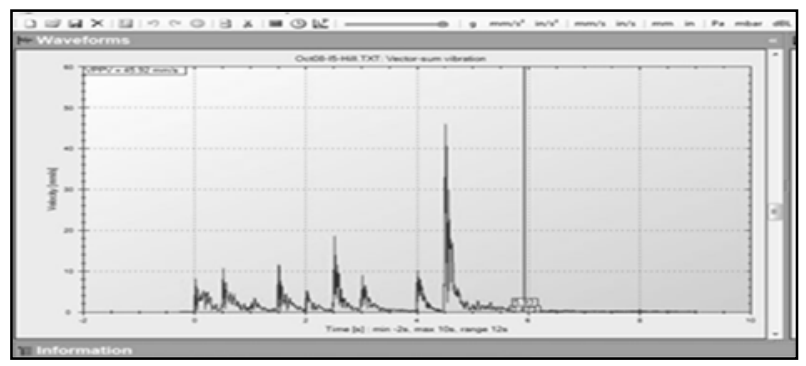

Fig. 4. PPV of different maximum instantaneous charge (Waveform of signature shot)

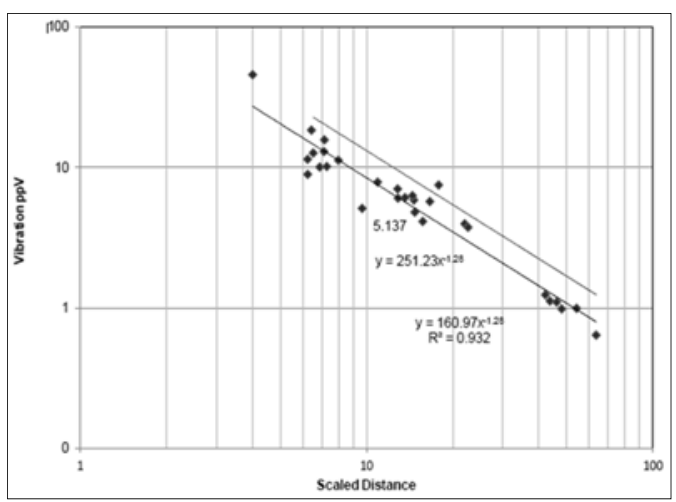

Fig. 5. Model established after regression analysis 
Hence, the PPV equation for south quarry is:

$$
\mathrm{PPV}=251 \mathrm{X} \mathrm{SD}^{-1.28}
$$

Based on the above equation certain field trials were also taken and it yielded an accuracy of almost $90 \%$ with the predicted vibration.

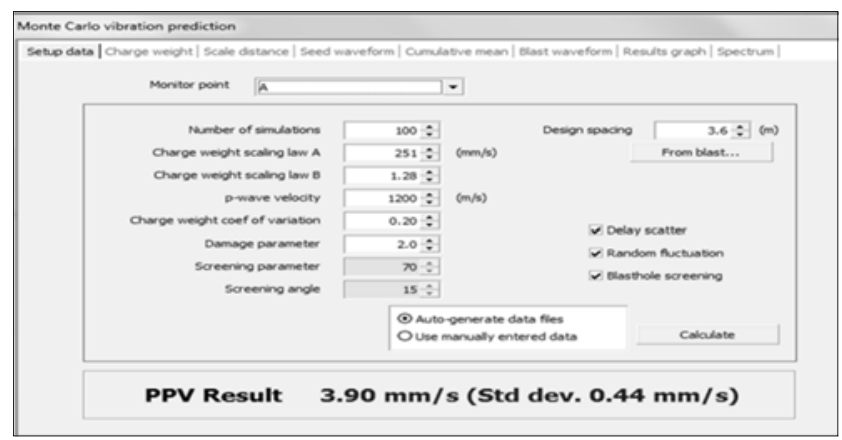

Fig.6. Standard deviation of $0.44 \mathrm{~mm} / \mathrm{s}$ between actual and predicted vibration

The above regression analysis model is a very good indicator of ground vibration management and it helped in devising the charging methods.

\section{Advanced Blasting Technique to improve productivity}

Till now the safe methods of blasting were devised for south quarry but on blast fragmentation part some improvement was still required. Electronic detonators afford unparalleled accuracy, flexibility and security to the initiation of Blasts. It has long been understood that different Blast delay timings can drastically change Blast results. Conventional delay sequencing of blasts is achieved using pyrotechnic delay detonators and connectors, which have an inherent variation in their delay accuracy. Use of these systems is engineered to firstly give firing in sequence and then timings within and between rows to achieve better fragmentation even with $40 \%$ expanded pattern. It contributes to better and predictable shockwave reinforcement between the holes. Till now the safe methods of blasting were devised for south quarry but on blast fragmentation part some improvement was still required. The design pattern was expanded from $25 \%-40 \%$ depending upon the type of rock and the results were recorded and complied wrt to the KPIs.

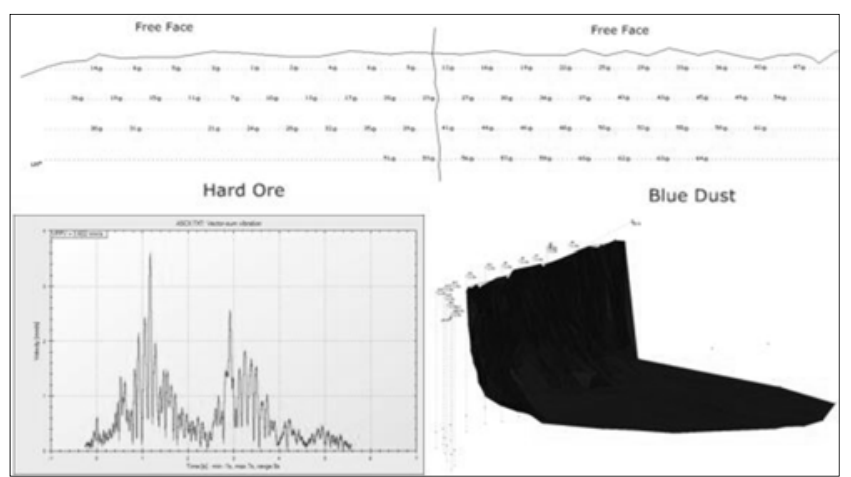

Fig.7. Blast design with drill pattern expansion
The fragment size analyses were carried out with the help of Wipfrag software of M/s Wipware Inc., Canada. The output of the analyses is in the form of number of exposed fragmented blocks, maximum, minimum and mean size of the fragmented blocks, sieve analysis as per the requirement i.e. at different percentile size viz. D10, D25, D50, D75 \& D90. (Percentile sizes: for example, D10 is the tenpercentile, the value for which $10 \%$ by weight of the sample is finer and $90 \%$ coarser. In terms of sieving, D10 is the size of sieve opening through which $10 \%$ by weight of the sample would pass. The outputs of the detail analyses of the fragment size are depicted in Figures $7 \& 8$. The average mean size of the block is $0.28-0.31 \mathrm{~m}$ (diameter of an equivalent sphere) and the most common size of the block is $0.15-0.26 \mathrm{~m}$ (diameter of an equivalent sphere) after excluding the fine size of the fragmented rock in analyses.

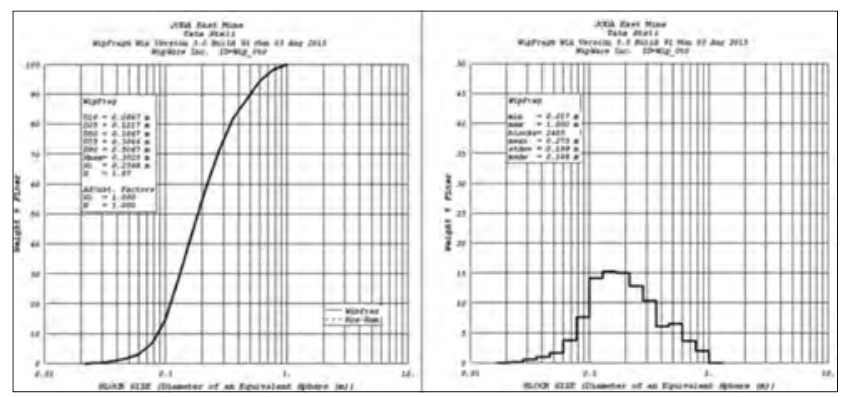

Fig.8. Histogram and cumulative size curve view of fragmented block sizes

\section{E. Co-relation of drilling andblasting parameters}

A detailed study was then carried out to co-relate the drilling and blasting parameters. Drill machines used for drilling are IDM 45, IDM 30 and ROCL8. Drilling is done with the help of button bits. Specific Energy (Es) can be defined as the energy necessary to drill a determined volume of rock $(\mathrm{GJ} / \mathrm{m} 3)$. The total amount of explosive consumed per hole is also recorded. A co relation between the above two parameters has been drawn to determine the optimal level of explosive consumption. Specific energy is calculated based on Nishimatsu's [11] model for specific energy calculation.

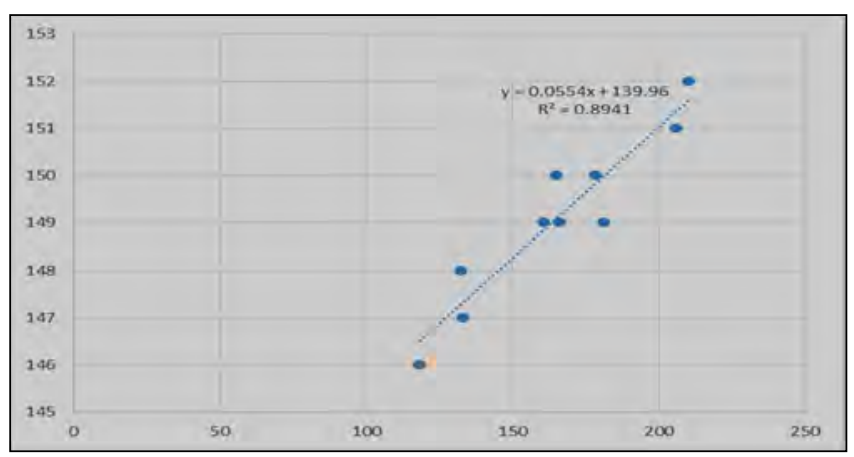

Fig. 9. Specific energy $\left(\mathrm{MJ} / \mathrm{m}^{3}\right)$ vs. Explosive charge $(\mathrm{kg})$

\section{RESULT AND INTERPETATION}

Productivity of excavators and dumpers are the most important element in improving the overall efficiency of mining operations. In a typical iron ore operation, quality is a 
major challenge and any improvement in the blasted inventory results in paramount shift in the cost curves too. Cost incurred in maintenance of HEMMs is also a major cost component. Hence it becomes very much essential to categorize the productivity and cost of mining operations for overall sustainable development.

\section{A. Improvementin HEMM Productivity}

A considerable improvement in shovel TPH (ton per hour) has been achieved through introduction of advanced vibration and blasting technique. The lead distance from south quarry to primary crushing unit is $3.5 \mathrm{~km}$. EX -1200 hydraulic excavators of bucket size $5.5 \mathrm{~m}^{3}$ is used for excavation of hard ore. KOMATSU HD 785 100T dumpers are used for hauling of ROM.

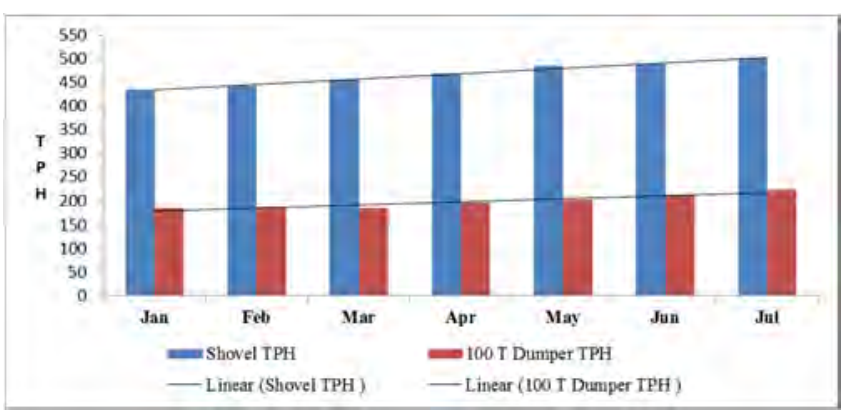

Fig.10. Shovel - Dumper TPH from south quarry (JEIM)

\section{B. Cost Improvements}

Different components of mining operation cost were interpreted to assess the scope of the project. Advance blasting technique with the help of electronic detonators and pattern expansion in drill geometry has resulted in cost savings which has been a notable outcome of the project.

In Fig. 11 Slope of D\&B cost is steeper than shoveling cost, so overall cost is dominated by $\mathrm{D} \& \mathrm{~B}$ cost. The optimal zone is the target area where the overall cost can be attained. Hence a suitable combination of shoveling and blasting operation can be devised for cost reduction initiatives. In Fig. 12 a comparison has been drawn over the pyrotechnic delay detonators and electronic detonators. $28 \%$ of the cost is shared by the later as compared to $1 \%$ of the total cost shared by pyrotechnic delay detonators. Hence a comprehensive approach for advance blasting technique was required to optimize the overall maintenance cost of drill and shovel and operation cost of drilling, blasting and shoveling.

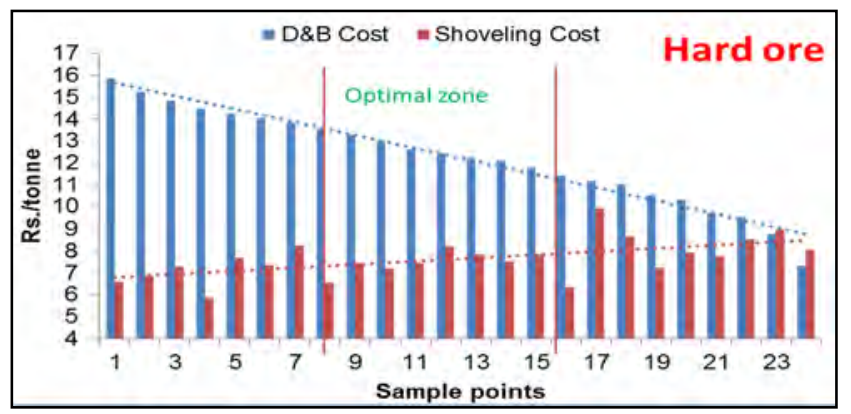

Fig.11. Cost comparison of D\&B cost vs. Shoveling cost

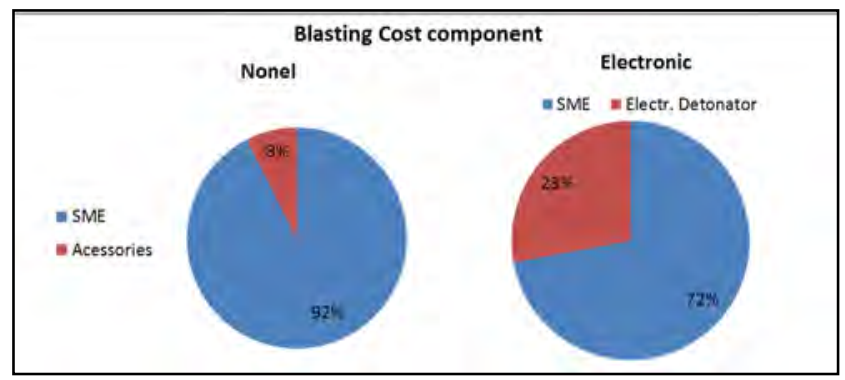

Fig.12. Pyrotechnic delay detonators vs. electronic detonators

It is evident from the results that significant reduction in drilling \& blasting cost is achieved in mining operation through advanced blasting technique and use of electronic detonators. Results of all blast shots are satisfactory with good fragmentation and throw. Field observations also indicated further scope of expansion. A varied range of reduction in drilling \& blasting costs are obtained depending upon rock strata

\section{CONCLUSIONS}

The annual blasted tonnage requirement for Joda east iron mine is approximately 10.5 MT. A large proportion of the mining operation cost is shared by explosive and its accessories. With the growing competition in manufacturing sector, cost effectiveness is broadly required for mining companies. The paper systematically highlights the safe methods for blasting to minimize the ground vibration. Generation of fly rock is nil due to accuracy level of detonators and efficient explosive charging methods. Simultaneously study was carried out depending on the pulldown pressure of drill machine to calculate the specific energy required for drilling rock and net explosive required per round of blast. This provided the suitable reconciliation on the part of the explosive charges required for advanced vibration management. Later, another level of advanced blasting technique was adopted with the help of electronic detonators to improve productivity and optimize the drilling - blasting and shoveling cost. A compilation of operation and maintenance cost was also done to identify the areas for improvement in mining operation. From Fig. 13 it is quite evident that a delta reduction of $18-27 \%$ can be achieved with the help of electronic delay detonators in rock strata having higher compressive strength.

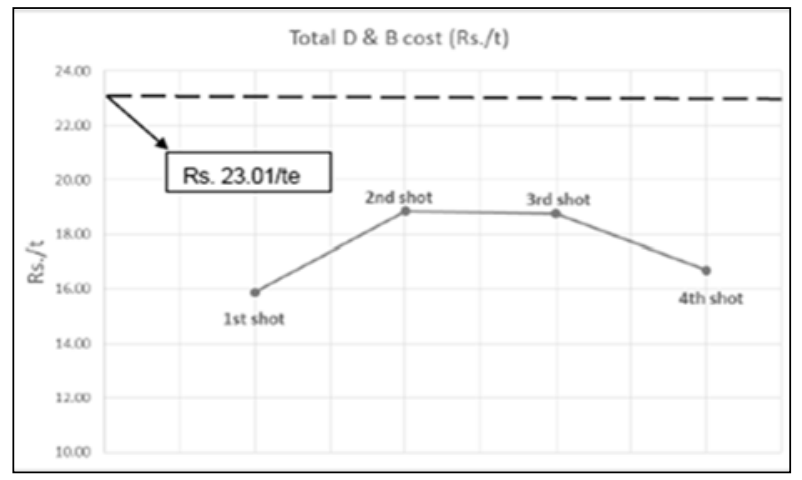

Fig.13. Cost Improvement summary 
Hence based on nature of rock strata and requirements of inputs for crusher, blast can be designed for increasing the throughput of excavators and optimizing the blasting cost. Electronic delay detonators are useful accessories for controlling the ground vibration and optimizing the blast fragmentation. A well-designed method for explosives charging and selection of delay timings results in desired blast outcome. Electronic delay detonators are a useful tool in achieving the cost effectiveness for sustainable development.

\section{REFERENCES}

[1] T.N.Little, and F.van Rooyen, The Current State of the Art of Grade Control Blasting in the Eastern Goldfields. Proceedings of the Aus. IMM Explosives in Mining Workshop. Aus. IMM. Melbourne, VictOlia. 1988. pp. 87-95

[2] C.V.B.Cunningham, The role of blasting instrumentation in promoting mine profitability, Proc. of the $3^{\text {rd }}$ international symposium on Rock Fragmentation by blasting, Brisbane, 26-31 August, pp245$250,1990$.

[3] Langefors, U. and Kihlström, B. (1963). The modern technique of rock blasting: Wiley New York

[4] DGMS Technical Circular No. 7, Standards of safe level of blast induced ground vibration for safety of structures, Ministry of Labour and Employment, Government of India, 1997.

[5] Pal Roy, "A comprehensive assessments of ground vibrations and structural damage caused by blasting," International conference on rock blasting -Fragblast, p.p 437,2010.

[6] Singh and Narendrula, "Causes, implications and control of oversize during blasting," Proceedings of the 9th International Symposium on Rock Fragmentation by Blasting, pp. 311-31,2009.

[7] http://miningandblastingfiles.wordpress.com/2009/09/blast-vibrationcoursemeasurementassessmentcontrol.pdf (as on 11/8/2016)

[8] Hino K. (1959), "Theory and Practice of Blasting”, Nippon Kayaku Co. Ltd. Japan.

[9] Barton N., Lien R. and Lunde J. (1974), "Engineering classification of rock for the design of tunnel support", Rock Mech., Vol -6, pp189236.

[10] Bieniawski Z. T. (1974), "Geomechanics classification of rockmass and application in tunneling", Proceedings third congress ISRM (Denver), Vol-2A, p27

[11] Nishimatsu Y (1972) The mechanics of the rock cutting. Int J Rock Mech Min Sci Geomech 9:261-271 